\title{
Soft X-Ray Emission Studies on Hydrate-Melt Electrolytes
}

Tatau Shimada $^{1}$, Norio Takenaka ${ }^{1,2}$, Eriko Watanabe ${ }^{1}$, Yuki Yamada ${ }^{1,2}$, Yi-Tao Cui ${ }^{3}$, Yoshihisa Harada $^{3,4}$, Masashi Okubo ${ }^{1,2}$, Atsuo Yamada ${ }^{1,2 *}$

1. Department of Chemical System Engineering, The University of Tokyo, 7-3-1, Hongo, Bunkyo-ku, Tokyo 113-8656, Japan

2. Elements Strategy Initiative for Catalysts \& Batteries (ESICB), Kyoto University, 130 Goryo-Ohara, Nishikyo-ku, Kyoto 615-8245, Japan

3. Institute for Solid State Physics, The University of Tokyo, 5-1-5, Kashiwanoha, Kashiwa-shi, Chiba 277-8581, Japan

4. Synchrotron Radiation Research Organization, The University of Tokyo, 1-490-2, Kouto, Shingu-cho, Tatsuno, Hyogo 679-5165, Japan

\section{Corresponding Author}

* E-mail: yamada@chemsys.t.u-tokyo.ac.jp (AY) 


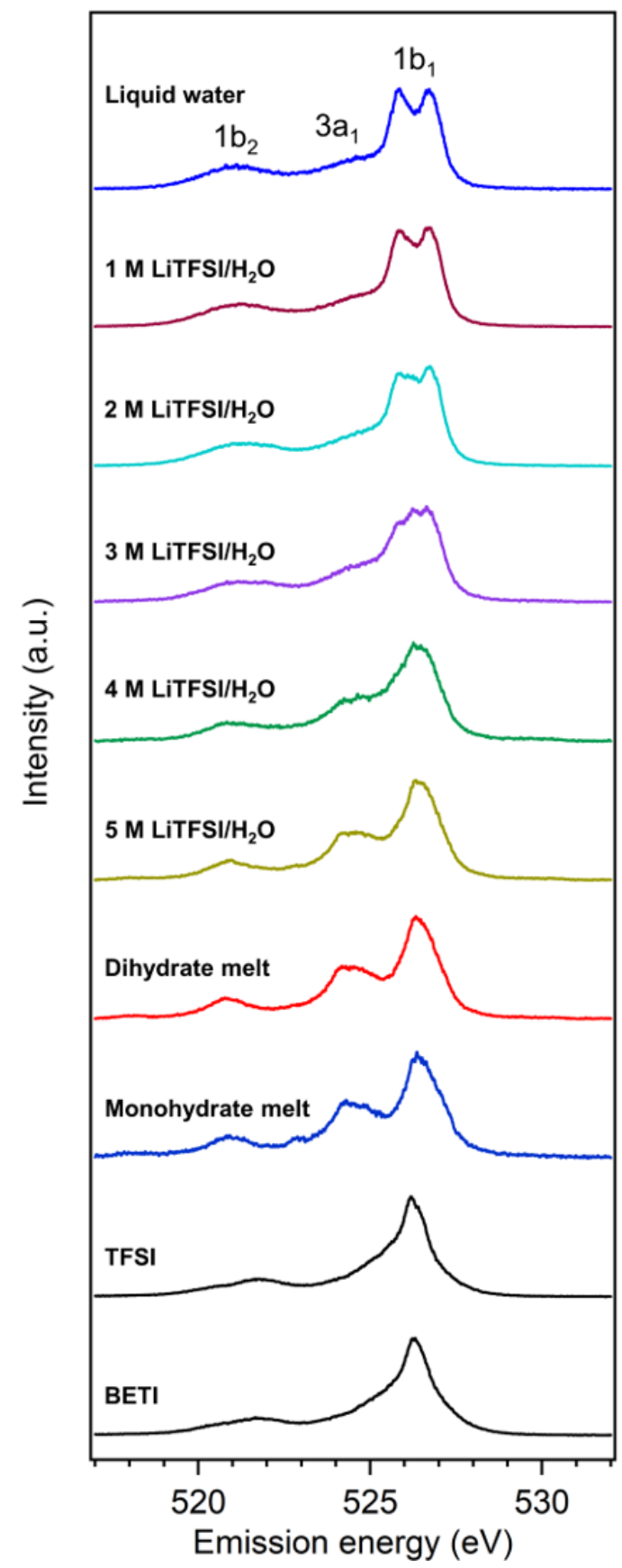

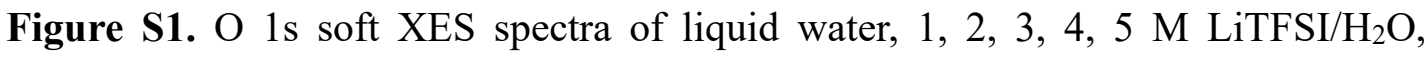
dihydrate melt, monohydrate melt, LiTFSI powder, and BETI powder. 

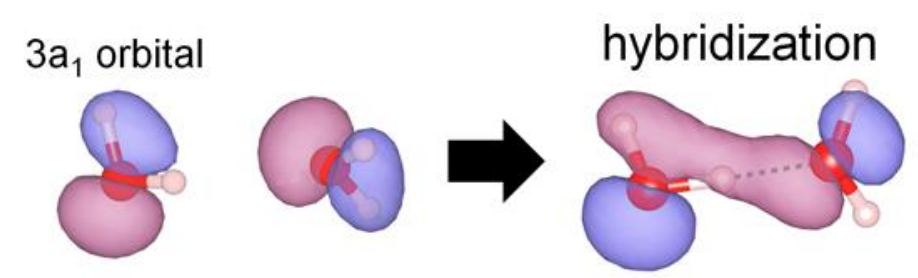

Figure S2. Schematic view of hybridization of $3 \mathrm{a}_{1}$ orbitals between water molecules. 


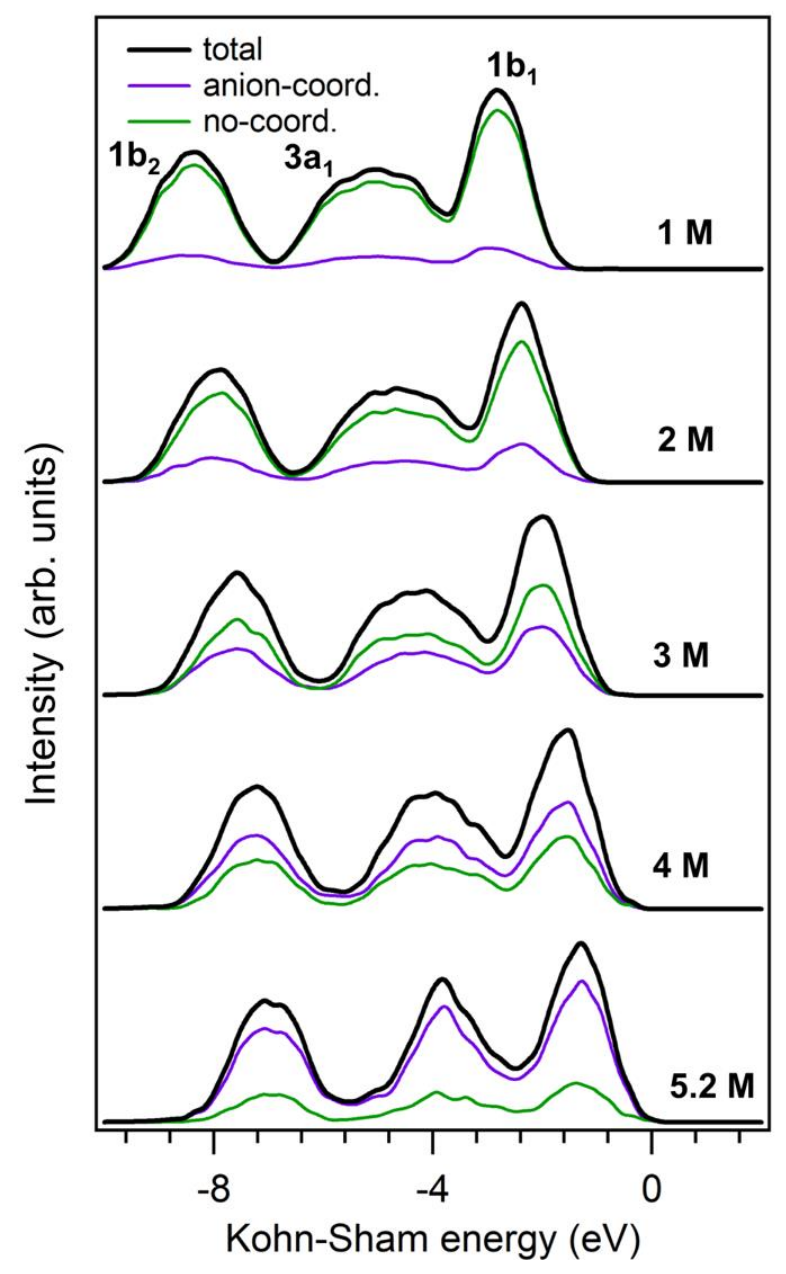

Figure S3. PDOS of water molecules in 1, 2, 3, 4, $5.2 \mathrm{M} \mathrm{LiTFSI} / \mathrm{H}_{2} \mathrm{O}$, and their components decomposed into those coordinate to anions ("anion-coord.") and those not coordinate to anions ("no-coord."). 
Table S1. Numbers of molecules/ions and side lengths of cubic supercells for MD simulations.

\begin{tabular}{ccccc}
\hline & No. of $\mathrm{H}_{2} \mathrm{O}$ & $\begin{array}{c}\text { No. of } \\
\text { TFSI/BETI }\end{array}$ & No. of Li & $\begin{array}{c}\text { Side length } \\
(\AA)\end{array}$ \\
\hline $1 \mathrm{M} \mathrm{LiTFSI} / \mathrm{H}_{2} \mathrm{O}$ & 191 & $4 / 0$ & 4 & 18.81 \\
$2 \mathrm{M} \mathrm{LiTFSI} / \mathrm{H}_{2} \mathrm{O}$ & 159 & $8 / 0$ & 8 & 18.79 \\
$3 \mathrm{M} \mathrm{LiTFSI} / \mathrm{H}_{2} \mathrm{O}$ & 127 & $12 / 0$ & 12 & 18.80 \\
$4 \mathrm{M} \mathrm{LiTFSI} / \mathrm{H}_{2} \mathrm{O}$ & 94 & $16 / 0$ & 16 & 18.80 \\
$5.2 \mathrm{M} \mathrm{LiTFSI} / \mathrm{H}_{2} \mathrm{O}$ & 50 & $20 / 0$ & 20 & 18.55 \\
dihydrate melt & 40 & $14 / 6$ & 20 & 18.74 \\
\hline
\end{tabular}


Table S2. Energy differences of $3 \mathrm{a}_{1}$ peaks with and without coordination to $\mathrm{Li}^{+}$in 1 M, $2 \mathrm{M}, 3 \mathrm{M}, 4 \mathrm{M}, 5.2 \mathrm{M} \mathrm{LiTFSI} / \mathrm{H}_{2} \mathrm{O}$ and dihydrate melt (diHM) electrolytes ( $\Delta E_{3 \mathrm{a}}$ $=E_{3 \mathrm{a}_{1}}$ (no-coord.) $-E_{3 \mathrm{a}_{1}}\left(\mathrm{Li}^{+}\right.$-coord.), where $E_{3 \mathrm{a}_{1}}\left(\mathrm{Li}^{+}\right.$-coord.) and $E_{3 \mathrm{a}_{1}}$ (no-coord.) are energies of $3 \mathrm{a}_{1}$ peak with and without coordination to $\mathrm{Li}^{+}$, respectively).

\begin{tabular}{lcccccc}
\hline & $1 \mathrm{M}$ & $2 \mathrm{M}$ & $3 \mathrm{M}$ & $4 \mathrm{M}$ & $5.2 \mathrm{M}$ & $\mathrm{diHM}$ \\
\hline$\Delta E_{3 \mathrm{a}_{1}}(\mathrm{eV})$ & 0.44 & 0.84 & 0.62 & 0.72 & 0.64 & 0.86
\end{tabular}

